\title{
ReaR

\section{Recomendaciones sobre la utilización del taponamiento faríngeo en adultos. Revisión sistemática y documento de consenso}

Artículo original: Systematic review of benefits or harms of routine anesthetist-inserted throat packs in adults: practice recommendations for inserting and counting throat packs. Athanassoglou V, Patel A, McGuire B, Higgs A, Dover MS, Brennan PA, Banerjee A, Bingham B and Pandit JJ. Anaesthesia 2018, 73, 612-618 (PubMed)

An evidence-based consensus statement by the Difficult Airway Society (DAS), the British Association of Oral and Maxillofacial Surgery (BAOMS) and the British Association of Otorhinolaryngology, Head and Neck Surgery (ENT-UK).

Zugasti Echarte O (1), Dufur Mendívil M (2).

(1) Complejo Hospitalario de Navarra.

(2) Hospital San Juan de Dios. Pamplona.

\section{Resumen}

El taponamiento faríngeo es un procedimiento habitual realizado por los anestesistas tras la inducción anestésica en cirugía dental, maxilofacial, nasal y de vía aérea superior. No obstante, parece no haber una clara evidencia que apoye esta práctica. El propósito principal de este artículo es contestar a la pregunta: ¿Cuál es la evidencia que sustenta la colocación del taponamiento faríngeo por parte de los anestesistas?

Para ello se llevó a cabo una revisión sistemática y búsqueda bibliográfica, que no consiguieron encontrar evidencia científica de calidad que avalase el uso del taponamiento. Sin embargo, se encontraron varios artículos en los que se exponían complicaciones de diversa gravedad y se ofrecían recomendaciones sobre cómo evitarlas.

Tras los resultados de esta búsqueda, los autores del estudio no recomiendan la inserción rutinaria del taponamiento por parte de los anestesistas y aconsejan una indicación cuidadosa. Se presenta un protocolo de inserción del taponamiento.

\section{Introducción}

El taponamiento faríngeo es un procedimiento habitual realizado por los anestesistas tras la inducción anestésica en cirugía dental, maxilofacial, nasal y de vía aérea superior. No obstante, parece no haber una clara evidencia que apoye esta práctica. El propósito principal de este artículo es contestar a la pregunta: ¿Cuál es la evidencia que sustenta la colocación del taponamiento faríngeo por parte de los anestesistas?

Para ello se llevó a cabo una revisión sistemática y búsqueda bibliográfica, que no consiguieron encontrar evidencia científica de calidad que avalase el uso del taponamiento. Sin embargo, se encontraron varios artículos en los que se exponían complicaciones de diversa gravedad y se ofrecían recomendaciones sobre cómo evitarlas.

Tras los resultados de esta búsqueda, los autores del estudio no recomiendan la inserción rutinaria del taponamiento por parte de los anestesistas y aconsejan una indicación cuidadosa. Se presenta un protocolo de inserción del taponamiento. 
El empleo de un taponamiento faríngeo tras una intubación traqueal se ha convertido en una práctica rutinaria en cirugía dental, maxilofacial, nasal y de vía aérea superior. El propósito principal es absorber sangre y otras secreciones para mantener la vía aérea libre antes de la extubación.

En términos generales hay 6 razones para introducir un taponamiento faríngeo:

1. Prevenir una fuga aérea. Esta indicación es más frecuente en niños y no es tenida en cuenta para la realización de las recomendaciones de este artículo.

2. Prevenir la contaminación de la vía aérea inferior.

3. Evitar el goteo de vasoconstrictores líquidos vía nasal hasta la orofaringe.

4. Hemostasia y protección, por ejemplo, en cirugía láser.

5. En cirugía nasal con mascarilla laríngea flexible.

6. Evitar la entrada de sangre en el estómago, que puede provocar náuseas $\mathrm{y} \quad$ vómitos posoperatorios.

Un riesgo importante asociado al taponamiento es que si se olvida retirarlo tras la cirugía puede ocasionar una obstrucción completa de la vía aérea. Recientemente el NHS británico lo introdujo dentro del concepto de "eventos que nunca deberían ocurrir", definidos como incidentes graves, previsibles y que no deberían ocurrir si se emplean las medidas preventivas de seguridad adecuadas (1).

Para evitar este problema se han descrito varios métodos en la literatura, entre otros:

Dejar visible en la boca una parte del taponamiento.
- Atar o suturar el taponamiento al tubo endotraqueal.

Colocar etiquetas recordatorias en el paciente, en el tubo endotraqueal, en la máquina de anestesia o en todos ellos.

- $\quad$ Asegurarse de utilizar taponamientos radiopacos especialmente diseñados para facilitar su localización.

- Detallar la colocación del taponamiento o bien en la lista de verificación quirúrgica o en el contaje quirúrgico.

El riesgo de que el taponamiento no sea retirado aumenta con factores como las distracciones, las situaciones de emergencia, los cambios de personal, la necesidad de añadir otro taponamiento o una recuperación anestésica más rápida de la esperada.

Los mismos textos que describen cómo realizar la inserción de un taponamiento insisten en que, una vez utilizado, se debe comprobar la vía aérea utilizando laringoscopia directa para verificar que el taponamiento ha sido retirado por completo, así como para aspirar sangre y secreciones antes de la extubación (2).

\section{Métodos}

En nombre de tres importantes instituciones británicas (Difficult Airway Society (DAS), British Association of Oral and Maxillofacial Surgery (BAOMS) y British Association of Otorhinolaryngology, Head and Neck Surgery (ENT-UK)) se realizó una búsqueda en PubMed en septiembre de 2016 de acuerdo a las guías PRISMA, completadas con guías de referencias de varios textos de práctica anestésica general. Los criterios de inclusión fueron: publicaciones en inglés en relación con un potencial 
beneficio de la utilización del taponamiento faríngeo en anestesia. Quedaron excluidos los textos referentes al taponamiento fuera de la práctica anestésica.

Tras esta búsqueda inicial, se buscaron informes de casos en los que la no utilización del taponamiento hubiera provocado algún daño, como obstrucción de la vía aérea por hemorragia, que pudiera haber sido evitado con su uso. No se encontró ningún resultado.

En agosto de 2017, se realizó otra búsqueda para intentar encontrar artículos que no hubieran sido incluidos en la primera.

\section{Resultados}

En total se identificaron 45 publicaciones como potencialmente relevantes. De estas, la mayoría comunicaban complicaciones de los taponamientos faríngeos o de sus no retirada al final de la cirugía: obstrucción de vía aérea, entrada en el esófago/estómago, lesión de nervios faríngeos e incluso un fallecimiento.

Varios artículos discutían específicamente métodos para evitar la permanencia del taponamiento tras la cirugía, o complicaciones posteriores. Se encontraron cinco revisiones de práctica clínica y varios artículos que estudiaban el impacto del taponamiento faríngeo en las náuseas y vómitos posoperatorios.

No se encontraron estudios sobre la eficacia del taponamiento faríngeo llevado a cabo por anestesistas. Se identificaron cuatro ensayos clínicos, metodológicamente defectuosos, que concluían que había una evidencia muy débil respecto a su uso en cirugía, incluso en cirugía nasal.
Dos encuestas (3, 4) mostraron resultados interesantes: tan solo un tercio de los cirujanos y de los anestesistas nunca habían usado un taponamiento faríngeo, pero aproximadamente la mitad de los encuestados referían conocer o haber sufrido problemas con la no retirada accidental del mismo. También se mostró desacuerdo sobre quién debe ser el responsable de la retirada del taponamiento.

Por tanto, aunque los 45 estudios potencialmente relevantes proporcionaron a los autores un conocimiento básico del asunto, ninguno fue decisivo a la hora de contestar a la cuestión principal sobre la utilidad del taponamiento.

\section{Discusión}

El resultado principal de esta investigación es que parece no existir evidencia que sustente el empleo del taponamiento faríngeo por indicación anestésica, a la par que se ponen en evidencia complicaciones derivadas de su utilización.

Es destacable la ausencia de estudios en los que se evalúe concienzudamente la capacidad real del taponamiento para absorber sangre o secreciones. En su lugar algunos estudios relacionan la presencia de náuseas y vómitos posoperatorios (NVPO) con la presencia de sangre en la faringe (5). Sin embargo, las NVPO tienen un origen multifactorial y es muy difícil achacar su aparición a una sola circunstancia. En mi experiencia, en la práctica clínica habitual el taponamiento aparece prácticamente libre de sangre $\mathrm{o}$ secreciones cuando se retira en cirugía nasal programada. Sin embargo, en otras cirugías como la ortognática o las urgencias de otorrinolaringología ORL- (epistaxis incoercibles, sangrados postquirúrgicos...) sí que suele aparecer 
empapado en sangre, por lo que en estos casos parece ejercer una función importante impidiendo el paso de sangre a la vía aérea inferior.

Los autores del artículo reconocen que sería recomendable realizar ensayos clínicos, aunque insisten en que no parece que exista lugar para la inserción de rutina del taponamiento faríngeo en cirugía de vía aérea superior o de cabeza y cuello. Uno de los argumentos que esgrimen es que los cirujanos responsables en estos escenarios son expertos en la resolución de las potenciales complicaciones derivadas de su no utilización. En este sentido se puede discrepar, ya que, si bien los cirujanos pueden ser expertos en resolver una vía aérea quirúrgica, otras complicaciones, como por ejemplo un laringoespasmo, exigen una respuesta del anestesista.

Se incide en el artículo en que, si se juzga esencial la colocación de un taponamiento faríngeo, este debe ser colocado por el cirujano principal como parte del protocolo quirúrgico y así pase a formar parte del contaje de gasas y compresas (Ilustración 1).

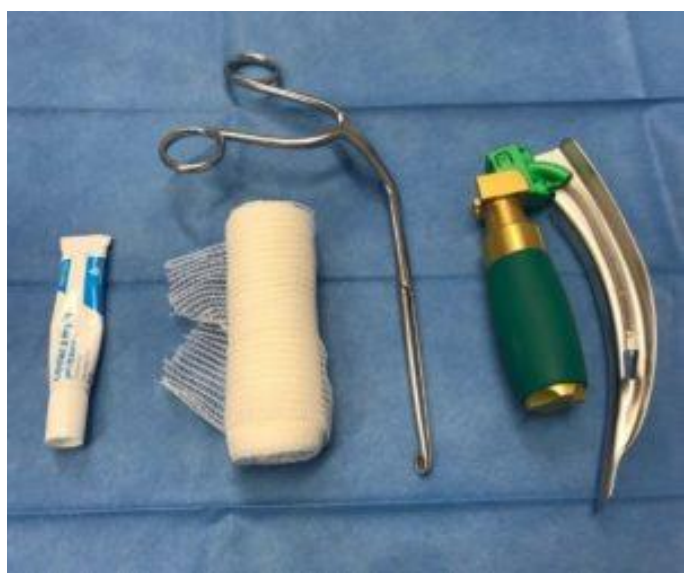

Ilustración 1. Material para la realización de un taponamiento faríngeo.

Estiman que en las cirugías en las que la orofaringe queda fuera del campo quirúrgico, como en cirugía nasal, puede ser razonable su colocación por parte del anestesista. En este caso se debería utilizar material que pertenezca al contaje quirúrgico y si se abre algún otro paquete (por ejemplo, si el tamaño de las gasas o compresas no es el adecuado), éste deberá formar parte del contaje.

A continuación, en la Ilustración 2, se reproduce el protocolo que los autores del artículo recomiendan en cuanto a la inserción del taponamiento.

¿Es realmente importante quién realiza el taponamiento? Es razonable pensar que, si no existe ninguna indicación puramente anestésica para hacerlo, sea el cirujano el que lo ejecute. Lo fundamental es otorgar al taponamiento la misma importancia que al resto del material empleado en la cirugía, y eso probablemente se consiga si se incluye dentro del protocolo quirúrgico y del contaje. Así, el cirujano se responsabiliza de retirar el taponamiento al final de la intervención para cuadrar el contaje y el anestesista se encarga de comprobar la vía aérea antes de la extubación. En nuestra opinión sí es importante compartir la responsabilidad de la correcta indicación y retirada del taponamiento, aumentando de esta manera la seguridad del paciente.

En el artículo los autores mencionan que una de las indicaciones del taponamiento faríngeo es la utilización de mascarilla laríngea. Sin embargo, hace ya más de 20 años que se describió el uso de la mascarilla laríngea reforzada para cirugía ORL, no sólo nasal sino también para amigdalectomías y adenoidectomías. Muchos estudios, incluido un metaanálisis reciente (6), describen cómo la mascarilla laríngea protege de manera efectiva la vía aérea de la contaminación por sangre o secreciones, sin necesidad de asociar un taponamiento. Por lo tanto, parece que en cirugía ORL programada podemos 
utilizar con seguridad los dispositivos supraglóticos y así ahorrarnos la utilización de un taponamiento que puede ser problemático.

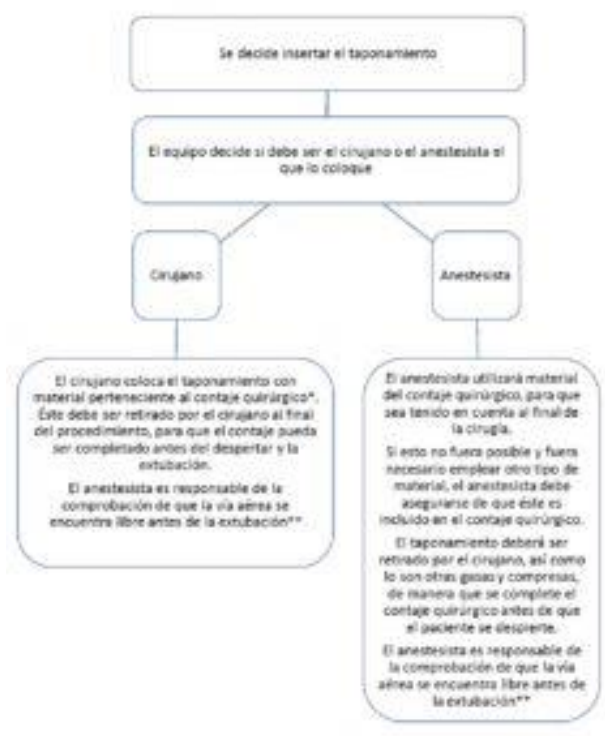

Ilustración 2. Protocolo de consenso para la inserción de un taponamiento faríngeo. ${ }^{*} \mathrm{El}$ anestesista puede ser reclamado para ayudar a la colocación del taponamiento, por ejemplo, mediante laringoscopia **exceptuando los casos donde se realiza un cerclaje mandibular completo, el paciente se traslada intubado a UCI o el taponamiento no es retirado deliberadamente.

En conclusión, en cirugía programada de cabeza y cuello, especialmente en aquella que se realiza en régimen ambulatorio, pensamos que los dispositivos supraglóticos pueden tener ventajas sobre la intubación oral y la inserción del taponamiento. Para cirugías más complejas o urgentes habrá que valorar la necesidad de la colocación del taponamiento, que preferiblemente será colocado y retirado por el cirujano, con posterior comprobación del estado de la vía aérea por parte del anestesista.

Pensamos que es importante realizar estudios como este, en el que se ponen en duda aspectos de la práctica diaria que pueden estar más basados en la tradición o en la rutina que en la evidencia científica.

\section{Bibliografía}

1. Surgical caseload and the risk of surgical Never Events in England. Moppett IK, Moppett SH. Anaesthesia 2016; 71: 17-30. ( PubMed) (HTML)

2. Oxford Textbook of Anaesthesia for Oral and Maxillofacial Surgery. Shaw I, Kumar C, Dodds C. Oxford: Oxford University Press, 2010.

3. Current practice and opinions regarding the use of oropharyngeal throat packs in the United Kingdom. Bisease B, Matthews NS, Lan C. Journal of Patient Safety 2011; 7: 1624. (PubMed)

4. Retained throat packs: results of a national survey and the application of an organizational accident model. Knepil GJ, Blackburn CW. British Journal of Oral and Maxillofacial Surgery. 2008; 6: 473-6. (Abstract)

5. Effectiveness of hypopharyngeal packing during nasal and sinus surgery in the prevention of PONV. Piltcher O, Lavinsky M, Lavinsky J, de Oliveira Basso PR. Otolaryngology Head and Neck Surgery 2007; 137: 552-4. (PubMed)

6. Airway Complications during and after General Anesthesia: A Comparison, Systematic Review and Meta-Analysis of Using Flexible Laryngeal Mask Airways and Endotracheal Tubes. Rui $\mathrm{Xu}$, Ying Lian,Wen Xian Li. PLoS One. 2016; 11(7): e0158137. (․MTML)

Correspondencia al autor

Orreaga Zugasti Echarte orreaga.zugasti.echarte@,cfnavarra.es F.E.A. Anestesiología y Reanimación. Complejo Hospitalario de Navarra.

Aceptado para el blog en noviembre de 2018. 